Sciendo

10.2478/abcsj-2021-0008

\title{
Self-Mention in Science Communication Associated with COVID-19 Research: A Comparison of Computer-Mediated Communicative Practices in the United Kingdom and the United States of America
}

\author{
OLEKSANDR KAPRANOV
}

Nordic Institute for Advanced Study - Strömstad Academy, Sweden

\begin{abstract}
The article introduces and discusses a corpus-assisted study that sets out to identify and analyse how self-mention is employed in science communication associated with COVID-19 research disseminated to the general public by leading universities in the United Kingdom (the UK) and the United States of America (the USA). The corpus of the study is comprised of computer-mediated communication related to the COVID19 pandemic on the official websites of Johns Hopkins University (the USA) and University College London (the UK). The corpus was examined quantitatively for the presence of self-mentions, such as $I, m y$, me, mine, myself, and we, our, ours, ourselves, and us. The results of the quantitative analysis indicated that computer-mediated communicative practices associated with COVID-19 discourse and communication by these scientific institutions exhibit similarities in terms of the use of selfmentions. However, in contrast to COVID-19-related discourse communicated by Johns Hopkins University, the self-mention $I$ and its forms were used more liberally in COVID-19-related discourse and communication disseminated by University College London. These findings are further discussed in the article from the vantage point of the current Anglo-Saxon tradition of academic writing in English.
\end{abstract}

Keywords: academic discourse, authorial presence, computer-mediated communication, corpus-assisted research, COVID-19-related discourse, pandemics communication, self-mention, science communication, university research centres 


\section{Introduction}

This article presents and discusses a study that aims to shed light on how self-mentions are employed in science communication associated with COVID-19 research that is disseminated to the general public by two leading universities in the United Kingdom (the UK) and the United States of America (the USA). The study is embedded into the theoretical view of the central role of language in healthcare research and practices, given that language, in particular scientific discourse, is employed in order to understand, diagnose, and communicate about infectious diseases and pandemics, such as the current COVID-19 pandemic (Semino 50). This study is commensurate with the American, British and Canadian Studies' focus on exploring "disciplinary developments in Anglophone Studies in the changing environment forged by the intersections of culture, technology and electronic information" (American, British and Canadian Studies). In harmony with the journal's focus, the study seeks to explore a discursive intersection between COVID-19-related research (i.e., technology and biotechnology) and its communication by computermediated means (i.e., electronic information) by two universities that are renowned both for their medical schools and COVID-19 research in the Anglophone world and internationally, Johns Hopkins University (the USA) and University College London (the UK).

The study is informed by the following theoretical premises, namely i) the role of self-mention in academic discourse as a manifestation of the authorial presence and identity (Ivanič 76), and ii) the approach to health communication associated with pandemics that is proposed by Brigitte Nerlich (15). Whereas these theoretical premises will be further expanded upon in the subsequent sections of the article, it should be noted that this study is based upon the understanding of selfmention in academic discourse as a pragmatic feature that is expressed by means of the first-person pronouns (for instance, I, me, my, we, us, and our) that are employed to manifest the authorial presence in an academic text and contribute to structuring the text rhetorically (Hyland "Humble Servants?" 211). The other theoretical premise in this study involves Nerlich's (16) approach to the communication of pandemics and 
infectious diseases, which is characterised by insights from social sciences, discourse analysis and communication research (Nerlich and Koteyko 712).

In line with the previously mentioned theoretical tenets, I set out to explore the use of self-mention in the corpus of computer-mediated texts associated with the COVID-19 pandemic that are found on the web sites of the COVID-19 research centres of Johns Hopkins University (further in the article abbreviated as $\mathrm{JH}$ ) and University College London (henceforth - UCL). The corpus of computer-mediated texts in the study has been collected in accordance with the understanding of computer-mediated communication (CMC) that "includes all modes of text-based humanhuman interaction mediated by networked computers or mobile telephony" (Bieswanger 463). It involves web sites, online discussion fora, online texts, and weblogs (Pikhart 121; Zou and Hyland 267). In line with this view of CMC, the corpus in the present study consists of JH's and UCL's CMC which is related to COVID-19 and disseminated online via the web sites of the COVID-19 research centres of these two universities.

Science communication associated with the current COVID-19 pandemic (Jaspal and Nerlich 249), as well as pandemics in general (Nerlich 15; Nerlich et al. 90; Nerlich and Koteyko 710), involves complex and conflicting narratives (Lambrecht 94). Arguably, discourse and communication associated with the ongoing COVID-19 pandemic could be operationalised as a complex discursive space that is comprised of medical discourse (French and Lyne 291; Webber-Ritchey et al. 13), social media discourse (Wicke and Bolognesi 1), identity-related discourse (Jaspal and Nerlich 249; Zhu 607), and discourse of risk communication (Lambrecht 96). Presumably, scientific communication of COVID-19-related discourse would be reflective of the aforementioned complex narratives that, among other facets, are associated with how a high-profile university research centre communicates its research in relation to COVID-19 to the general public. In this regard, the critical question would be whether or not such communication is discursively presented as a collective endeavour (i.e., the university's research centre would communicate COVID-19 research as a collective we-narrator), or as an individual undertaking that embodies the university research 
centre's discourse that is disseminated through the lenses of an I-narrator (i.e., a personified human agent, for instance, a researcher). Following this contention, it is possible to theorise that the university research centre's discourse concerning COVID-19 could be, potentially, communicated through the lenses of the we-narrator and the associated self-mentions we, our, us, etc., or, alternatively, as the $I$-narrator whose presence is manifested by such self-mentions as $I, m y$, mine, etc.

I assume in this study that the use of self-mentions in the corpus would be identical and/or very similar between JH and UCL, since these two universities are situated in the countries where English is either the official language, in the case of the UK, or spoken by the majority of people who consider it a mother tongue, as in the USA. In line with the aforementioned assumption, the following research questions are formulated in the study:

RQ1: Would self-mentions occur in the corpus of computermediated texts on the JH and UCL web sites associated with the COVID-19 pandemic?

RQ2: Would there be potential quantitative differences in the occurrence of self-mentions between the sub-corpora of computermediated texts associated with the COVID-19 pandemic communicated on the JH and UCL web sites?

Informed by these two research questions, this article will proceed as follows. First, the notion of self-mention in academic discourse will be provided. Thereafter, science communication associated with the COVID19 pandemic will be outlined. Then, the study will be introduced and discussed. The article will be concluded with the summary of the major findings and their significance in light of the COVID-19-related discourse.

\section{Self-mention in Academic Discourse: Literature Review}

Whereas the study of self-mention as a manifestation of the authorial presence in discourse harkens back to the pioneering publications by 
Mikhail Bakhtin (61-81) and Michel Foucault (16-49), research on selfmention in academic discourse written in the English language bears the mark of seminal publications by Roz Ivanič and Ken Hyland ("Humble Servants"). In the wake of Ivanič and Hyland ("Humble Servants?," "Authority and Invisibility," "Self-citation and Self-reference"), research studies that involve self-mention in academic discourse have received heightened attention in academia (Junnier; Palander-Collin and Nevala; Szczygłowska). As I previously mentioned in the introductory part of the article, this research is based upon the understanding of the role of selfmention in academic discourse posited by Hyland ("Humble Servants?," "Authority," "Self-citation") and Ivanič. Whilst Hyland ("Humble Servants?") carries out quantitative corpus-based studies of self-mention in academic discourse, the qualitative approach to self-mentions formulated by Ivanič problematises the use of self-mentions in academic discourse as a cross-fertilised space of discourse and identity. Despite these differences, however, both Hyland ("Humble Servants?") and Ivanič seem to regard self-mention as a manifestation of the authorial presence and authorial identity in an academic text.

It follows from Ivanič that self-mention in academic discourse is reflective of the notion of writer identity in a particular discourse community. Ivanič describes discourse communities as a social element of writer identity that involves discursive identification with the values and practices of a community (84). Ivanič argues that, typically, a writer adopts the intertextual practices of a particular discourse community, especially a discourse community which is associated with the academic writing executed in the English language (37). Ivanič posits that academic writers appear to adopt and adapt their writing style to particular traditions, sets of values, and language choices that characterise their discourse community (3). Specifically, it is indicated by Ivanič that

Academic discourse communities are constituted by a range of values, assumptions and practices. Individuals have to negotiate an identity within the range of possibilities for self-hood which are supported or at least tolerated by a community and inscribed in that community's communicative practices. Discourse community members, of varying affiliations in relation to the values, assumptions and practices, are also 
locked in complex interpersonal relationships, characterized by differences in status and power. (82)

According to Ivanič, one of the manifestations of the language choices imposed by the scientific community is the use of self-mentions that signal the author's presence in the text and explicitly mark the author's identity in relation to the textual piece. This contention is further expanded by Ivanič as "the identity of a person with authority," i.e., she seems to refer to the authorial presence in academic discourse within the parameters of authority (88). It is inferred from her seminal monograph that the current academic writing in English appears to be associated with an explicit and authoritative authorial presence, which is revealed in the text by such linguistic choices as the use of self-mentions $I$, we, etc. Moreover, Ivanič posits that

no writing is ever 'impersonal': whether writers like it or not, they are "giving off" an impression of themselves through their social action of writing, from the large-scale action of being involved in an act of writing of any sort, through the many social, cognitive and physical practices they engage in in order to do it, to the moment-by-moment linguistic choices they make in constructing their written message. (100)

Ivanič's observation that academic writing is never impersonal in the English-mediated discourse community (100) is further supported by Hyland ("Humble Servants?"). In accordance with Hyland (“Authority," "Self-citation"), the Anglo-Saxon discourse community is renowned for its current practices of manifesting authorial presence in academic texts. Hyland ("Humble Servants?") notes that these practices are fairly recent, given that the eradication of the authorial presence was considered a norm of Anglo-Saxon academic discourse 50 years ago, which was marked by an impersonal style, and "humility towards one's peers, one's reviewers, or the discipline in general" (Hyland "Humble Servants?" 208). However, the view of an academic writer as "a humble servant of the discipline" (208) has been superseded by the discursive shift towards an academic writer with identity, whose authorial presence is typically marked in an academic text by means of the explicit use of self-mentions, such as $I$, we, our, etc. (Hyland "Humble Servants?"). 
Hyland ("Humble Servants?," "Authority and Invisibility," "Self-citation and Self-reference") suggests that the current tendency to use explicit self-mentions in an academic text is reflective of the academic writer's stance and ownership of a scientific claim. Moreover, Hyland ("Humble Servants?," "Authority and Invisibility") argues that selfmentions (e.g., $I$ ) are an index of the academic writer's own contribution to the text, and, broadly, to the scientific discipline. Specifying this argument further, Hyland ("Humble Servants?") suggests that

The decision to adopt an impersonal rhetorical style or to represent oneself explicitly would seem to have significant consequences for how one's message is received. Indeed, the intrusion of authorial authority to limit claims, enhance plausibility, and promote personal credibility can play an important role in securing acceptance of academic arguments. (211)

It follows from Hyland's ("The Communication of Expertise") approach that the use of self-mentions in academic discourse is reflective of i) the discursive conventions of a particular scientific discipline (i.e., academic writers in the so-called "hard" sciences typically use less to none self-mentions, whereas their colleagues in the humanities tend to use self-mentions more liberally) and ii) the writer's authority that is used by the writer to "promote personal credibility" (Hyland "Humble Servants?" 211). In case of the latter, Hyland ("Self-citation") posits that selfmentions, alongside with self-references (e.g., this author) and selfcitations (i.e., when the author refers to their own work in the text) serve to i) enhance the authorial presence in an academic text and ii) facilitate the academic writer's self-promotion (Hyland "The Communication").

It should be noted that both Hyland's ("The Communication") and Ivanič's insights into self-mention in academic writing are used in the study. However, prior to proceeding to the study, let us consider recent research associated with COVID-19 discourse and communication, since it provides the background to the study.

Discourse and Communication Associated with COVID-19: Literature Review 
The emergence, spread, and containment of the contagious SARS-CoV-2 virus have dominated public discourse and science communication in 2020-2021 (French and Lyne 291). As previously mentioned in the introductory part of the article, discourse associated with the COVID-19 pandemic is represented by a complex discursive space (French and Lyne; Jaspal and Nerlich). The current literature indicates that its complexity rests with the paramount importance of science communication associated with COVID-19, especially as far as the containment and prevention of the virus spread are concerned (Jaspal and Nerlich; Semino). Another critical aspect of science communication about the COVID-19 virus is the dissemination of medical and health-related information that impacts upon the management of the pandemic and the people's behaviour under the lockdown due to the pandemic (Majumder and Mandl 627; Morgan 270).

Whilst COVID-19-related discourse is novel, there is a substantial line of prior studies that addresses various facets related to discourse and communication of infectious diseases and pandemics. This line of previous research elucidates discourse and science communication that involve the foot and mouth disease (Nerlich et al. 90), the SARS outbreak (Wallis and Nerlich 2629), and the swine (Nerlich and Koteyko 710) and avian flu epidemics (Koteyko et al. 242; Nerlich and Halliday). Arguably, the aforementioned studies share a common denominator that is based upon Nerlich's contention that the discourse about pandemics represents a heterogeneous discursive space that is comprised of public health communication, science communication, as well as risk and biosecurity communication (Nerlich and Koteyko 720). In this regard, Nerlich's approach to pandemics-related discourse appears to draw from a broad spectrum of social studies, discourse analysis, and political communication (720). It should be emphasised that the present research investigation is informed by the approach found in the publications by Nerlich and her colleagues (Nerlich et al.; Nerlich and Halliday; Nerlich and Koteyko) in the sense that it problematises language as a critical means of conceptualising and analysing discourse and science communication about the COVID-19 pandemic, which is disseminated by the coronavirus research centres of leading medical schools, such as JH and UCL, to a variety of stake-holders (e.g., the general public). 
In the wake of the on-going COVID-19 pandemic that has attracted considerable interest on the part of scientific community, I do not assume to provide an exhaustive account of the literature associated with COVID19-related discourse and communication. However, it seems possible to outline the current literature on COVID-19 discourse and communication that is based upon several common research themes, such as i) metaphor analysis (Semino), ii) frame analysis (Lambrecht; Wicke and Bolognesi), and iii) identity analysis (French and Lyne; Jaspal and Nerlich; Zhu).

The research theme of metaphor analysis in relation to discourse and communication of the COVID-19 pandemic permeates the recent publication by Elena Semino (50). She argues that metaphorical descriptions of the COVID-19 pandemic as a war, an enemy, and a fight have been widely used since the early start of the global spread of the coronavirus (Semino 51). Semino examines metaphors in a corpus of tweets that are associated with COVID-19 discourse. She has established that COVID-19-related discourse appears to be characterised by several metaphors that conceptualise COVID-19 as Fire, Journey, Tsunami, and War (Semino 50). It is argued by Semino that the corpus of COVID-19related tweets could be adequately described via the Fire metaphor, whereby medical staff are conceptualised as Fire-Fighters, who aim at extinguishing the coronavirus that is conceptualised as Fire. It should be noted that metaphoricity of pandemics-related communication is not a novel finding in discourse studies. Specifically, metaphor analysis has been previously applied to discourse associated with the foot and mouth disease, avian and swine flu, as evident from seminal publications by Nerlich and her colleagues (Nerlich and Halliday; Nerlich et al.; Nerlich and Koteyko).

The theme of scientific inquiry that employs framing analysis of COVID-19-related discourse is present in Kathryn Lambrecht (94) and Philipp Wicke and Marianna Bolognesi (1). Similar to Semino, Wicke and Bolognesi examine a corpus of tweets referring to COVID-19. However, in contrast to Semino, they use framing analysis in order to establish discussion topics and figurative framing of COVID-19-related discourse on Twitter. Wicke and Bolognesi (19) have found several main topics of tweets by the time of their article publication in the spring of 2020, 
namely "World," "Trump," "China," "News," "Lockdown," "Press," and "Media." In terms of the figurative framing, the frames War, Monster, Family, and Tsunami are reported to be among the most frequent framing strategies of communicating about the COVID-19 pandemic (Wicke and Bolognesi 18).

Analogous to Wicke and Bolognesi, Lambrecht (96) employs framing analysis of risk communication and risk management in the corpus of texts that is comprised of press releases, media advisories, transcripts, and statements about COVID-19. By means of applying framing analysis, she has established that the framing of risk communication in conjunction with the COVID-19 pandemic has changed over time starting with a broad and rather generic framing (e.g., "it is a virus") at the beginning of the pandemic to a more specific framing that targets particular population strata (e.g., "the elderly") in the spring of 2020.

The research theme of identity analysis in conjunction with COVID-19-related discourse is the focus of recent publications by Ian French and John Lyne (291), Rusi Jaspal and Brigitte Nerlich (249), and Hongqiang Zhu (607). In particular, French and Lyne investigate how mass media reporting about COVID-19 poses a threat to people with obsessive-compulsive disorders (OCD). French and Lyne (292) argue that the personality and identity of people with OCD appear to be affected by the media discourse associated with the COVID-19 pandemic. Also set within the scope of the research theme of identity analysis, Jaspal and Nerlich (249) refer to the social representation theory and the identity process theory in order to identify and classify the impact of COVID-19related discourse. Whilst Jaspal and Nerlich do not seem to state explicitly what constitutes their corpus of COVID-19-related discourse, they suggest that discursive representations of the COVID-19 pandemic could be construed as threatening, and, consequently, identity changing. In particular, they have established that fear limits the effectiveness of COVID-19 communication and impacts negatively upon a person's identity. By contrast, self-efficacy and social support have been found to be facilitative in protecting against threats to identity (Jaspal and Nerlich 249). A similar threat to identity against the background of COVID-19- 
related discourse is addressed by Zhu (607). According to Zhu (610), the threat could be problematised as the stigmatisation of the Chinese people by the mass media that equate the origin and spread of the coronavirus with China and the Chinese. Zhu (612) posits that there are segments of online discourse that are racist and ethnically biased towards the Chinese, who experience multiple threats and verbal abuse based on their ethnic identity.

It follows from the aforementioned meta-analysis of the literature that there is a growing body of research that focuses on the discourse and communication of the COVID-19 pandemic. Currently, however, there are no published studies that shed light on how micro-discursive means, such as self-mentions, are used in COVID-19-related discourse. The study further described in the article seeks to provide novel insights into the realm of self-mentions in relation to COVID-19 discourse and communication.

\section{The Present Study: Hypothesis and Research Questions}

The study seeks to elucidate how self-mentions are employed in COVID19-related discourse and communication, which are disseminated by the coronavirus research centres of the leading universities that are renowned both for their medical schools and the current COVID-19 research in the Anglophone world, namely JH (the USA) and UCL (the UK). As previously mentioned in the article, the study is informed by the view of self-mention as a micro-discursive pragmatic feature that is expressed by means of the first-person pronouns I, me, my, mine, myself, we, us, our, ourselves, and ours, which are employed in order to manifest the authorial presence in a text (Hyland "Humble Servants?" 211). Given that there is a well-established tendency in Anglo-Saxon academic discourse to use selfmention as a marker of authorial presence (Hyland "Humble Servants?"; Ivanič), this study seeks to establish whether or not the authorial presence in COVID-19-related discourse and communication by JH and UCL would bear the mark of a collective, or, alternatively, an individual authorial identity in the sense postulated by Ivanič. 
I hypothesise that both JH's and UCL's COVID-19-related discourse and communication would be characterised by an explicit authorial presence marked by the use of self-mentions, assuming that these two universities are situated in the countries where English is the official language and spoken by the majority of the population. Whilst I assume that COVID-19-related discourse and communication by $\mathrm{JH}$ and UCL would be characterised by the presence of self-mentions, it remains to be elucidated whether or not the to-be-identified selfmentions would be represented by the self-mention we and its associated forms (our, us, ours, ourselves), or by the self-mention $I$ and its respective forms (me, my, myself, mine), or both we and $I$. In line with the hypothesis, two specific research questions have been formulated in the introductory part of the article. Further, I describe the corpus and the methods used in the corpus analysis, as well as the results of the present investigation and their discussion.

\section{Corpus}

The corpus of the study was comprised of the online texts found on i) the JH's COVID-19 research centre website (Coronavirus Resource Center) and ii) the UCL's COVID-19 research website (COVID-19 Research at UCL). The corpus was collected within the timeframe from 1 October 2020 till 31 January 2021. It should be explained that the following links were excluded from the corpus: i) links that were external to the two respective universities, such as COVID-19-related news provided by mass media outlets, for instance, $\mathrm{BBC}, \mathrm{CNN}$, The Guardian, etc.; ii) links to podcasts that were produced by the respective university schools and departments other than the coronavirus research centres._The descriptive statistics of the corpus were processed as the so-called raw data (i.e., non-normalised data) in the statistical program Statistical Package for Social Sciences (SPSS), version 18.0 (IBM) and summarised in Table 1 below. 
Table 1. The Descriptive Statistics of the Corpus

\begin{tabular}{|l|l|l|l|}
\hline $\mathbf{N}$ & Descriptive Statistics & JH & UCL \\
\hline 1 & Total number of texts & 21 & 19 \\
\hline 2 & Total number of words & 19063 & 11059 \\
\hline 3 & Mean words & 907.8 & 582.1 \\
\hline 4 & Standard deviation & 1003.3 & 336.0 \\
\hline 5 & Minimum & 47 & 71 \\
\hline 6 & Maximum & 3232 & 1416 \\
\hline
\end{tabular}

Methods

Methodologically, the study was based upon the following procedure. First, the corpus of the study was collected. It was comprised of the respective JH and UCL websites associated with the COVID-19 research centres. Then, the online texts were converted into plain text files (.txt). I manually searched for the presence of self-mentions in the corpus in accordance with the definition of self-mention formulated by Hyland ("Humble Servants?" 211). Thereafter, self-mentions in the corpus were entered into SPSS, version 18.0 (IBM), as raw data in order to compute means and standard deviations of self-mentions in the corpus. Next, the raw data were normalised by means of applying a 10000 words cut-off and subsequently processed by means of using the computer program WordSmith (Scott) in order to establish the frequency of self-mentions per 10000 words. The normalisation of the data was deemed a necessary procedure due to the differences in the number of words in the subcorpora of texts by JH and UCL.

\section{Results}

The results of the quantitative analysis of the occurrence of self-mentions I, me, my, mine, myself, we, us, our, ours, and ourselves as raw data were summarised in Table 2. 
Table 2. Self-Mentions Means and Standard Deviations (SD) in the Corpus as Raw Data

\begin{tabular}{|l|l|l|l|}
\hline $\mathbf{N}$ & Self-Mentions Means and SD & JH & UCL \\
\hline 1 & I & $2.5($ SD 1.5) & $3.1($ SD 1.8) \\
\hline 2 & Me & 0 & 1 (SD 0) \\
\hline 3 & My & 0 & 1 (SD 0) \\
\hline 4 & Mine & 0 & 0 \\
\hline 5 & Myself & 0 & 0 \\
\hline 6 & We & $4.3($ SD 3.0) & $4.9($ SD 3.4) \\
\hline 7 & Us & $1.3($ SD 0.4) & $1.8($ SD 0.8) \\
\hline 8 & Our & $2.5($ SD 1.1) & $4.2($ SD 3.5) \\
\hline 9 & Ours & 0 & 0 \\
\hline 10 & Ourselves & 0 & $1($ SD 0) \\
\hline
\end{tabular}

Given the differences in the number of words in the sub-corpora of texts by JH and UCL, the data were normalised per 10000 words. The results of the normalised data were presented in Table 3 as the number of the occurrence and the percentage of the occurrence (provided in brackets) per 10000 words.

Table 3. The Frequency of Occurrence of Self-Mentions in the Corpus per 10000 Words

\begin{tabular}{|l|l|l|l|}
\hline $\mathbf{N}$ & Self-Mentions & JH & UCL \\
\hline 1 & $I$ & $9(0.09 \%)$ & $18(0.19 \%)$ \\
\hline 2 & Me & 0 & $4(0.04 \%)$ \\
\hline 3 & My & 0 & $2(0.02 \%)$ \\
\hline 4 & Mine & 0 & 0 \\
\hline 5 & Myself & 0 & 0 \\
\hline 6 & We & $42(0.42 \%)$ & $57(0.60 \%)$ \\
\hline 7 & Us & $16(0.16 \%)$ & $11(0.11 \%)$ \\
\hline 8 & Our & $2(0.02 \%)$ & $50(0.53 \%)$ \\
\hline 9 & Ours & 0 & 0 \\
\hline 10 & Ourselves & 0 & $1(0.01 \%)$ \\
\hline
\end{tabular}

Discussion

As previously assumed in the hypothesis, COVID-19-related discourse and communication disseminated by JH and UCL on these universities' 
web sites could be marked by an explicit authorial presence which is manifested by such self-mentions as $I$, we, etc. The results of the corpus analysis indicate that the hypothesis is supported. It has been established that JH's COVID-19-related discourse and communication are associated with the self-mentions $I$, we, us, and our, whereas COVID-19-related discourse and communication by UCL involve the self-mentions $I$, me, my, we, us, our, and ourselves (see Tables 2 and 3). Further, I intend to discuss these findings through the lenses of the two research questions (RQs) in the study, namely i) RQ1 that aims to establish whether or not self-mentions are present in JH's and UCL's COVID-19-related discourse and communication and ii) RQ2 that addresses the issue of quantitative differences between JH and UCL in terms of the occurrence of selfmentions.

Discussing RQ1: The Presence of Self-mentions in the Corpus

It is evident from Tables 2 and 3 that the corpus is marked by the presence of self-mentions, which supports the assumption formulated in the hypothesis. It seems feasible to offer the following explanations as far as the presence of self-mentions in the corpus is concerned. The first plausible explanation is based upon an observation that a university research web site nowadays presents itself as a culturally conditioned heterogeneous multimodal space (Pikhart 121) that is comprised of links to related web sites, online discussion fora, online reports and texts, and academic blogs (Zou and Hyland 269). In this regard, I agree with Hang Zou and Hyland, who posit that CMC, which is made public by a research-intensive university via its web site/sites, is regarded

as a means of disseminating research and attracting new, non-academic audiences or like-minded peers to new areas of scholarly activity. The heterogeneity and unfamiliarity of the audience means that writers need to present information in perhaps unfamiliar ways, creating an interest and encouraging them to engage with the topics. (267).

By means of elaborating upon Zou and Hyland's argument, I suggest that the use of self-mentions in CMC by a university, especially research-intensive universities such as JH and UCL, facilitates the 
dissemination of research in a personalised manner that, arguably, fosters engagement and interest of the public at large in the current COVID-19related research. Following this suggestion, it is possible to assume that the presence of the self-mentions in JH's and UCL's COVID-19-related discourse and communication renders the communicative style of these two universities a personalised dimension of their COVID-19-related narratives. The results of the data analysis indicate that JH's and UCL's discourse and communication about COVID-19 are manifested by the personalised dimension that can be described as the we-narrator in the sense postulated by Ivanič.

The collective identity of the we-narrator which is employed both by JH and UCL in disseminating their COVID-19 research is evident from the data that indicate that $w e$ is the most frequent self-mention in the corpus (Mean 4.3 by $\mathrm{JH}$ and Mean 4.9 by UCL in raw values; $\mathrm{N}$ per 10000 words $=42$ by $\mathrm{JH}$ and $\mathrm{N}$ per 10000 words $=57$ by UCL). The dominance of the we-narrator in COVID-19-related discourse and communication by JH and UCL could be regarded as the effort by these universities to portray themselves as scientific teams, collective entities that carry out COVID-19-related research in a communal manner. Presumably, the latter is depicted by the university as an institution and university staff who work in unison on the challenges presented by the coronavirus pandemic. The collective we-narrator is marked by the copresence of the self-mentions we and our in COVID-19-related discourse and communication by both JH and UCL, as seen in Excerpts (1) and (2) below, e.g.

(1) Our data provider, The Covid Tracking Project, is in the process of changing how it maps states' data to the categories we use for our positivity calculations. These changes mean the category of data we use in our denominator (Total tests) may now include tests previously not included in our calculations, which in turn may result in a test positivity calculation that is lower than what we would have calculated for the state prior to the change. With this significant change, we will once again review our data inputs and calculations to ensure that our numbers reflect the most responsible public health calculation of test positivity. (Daily State-by-State Testing Trends) 
(2) At UCL we are applying the depth and breadth of our crossdisciplinary research and expertise to help humanity recover from COVID-19 and to make the world more resilient and equitable in the future. Our experts are urgently researching new ways of tackling the COVID-19 pandemic and are taking a prominent role in advancing public knowledge by advising world leaders, collaborating with key partners and providing expert commentary to inform the media. (COVID-19 Research at UCL)

It follows from (1) and (2) that both $\mathrm{JH}$ and UCL present their COVID-19-related narratives by means of the self-mentions we and our in order to emphasise the role of the university as a team and a collective agent (e.g., "we use," "we are applying," etc.) that is actively involved in the process of COVID-19 research, containment and mitigation. In addition, it is inferred from (1) and, specifically, (2) that both JH and UCL tend to promote their COVID-19 narratives in a personalised manner, which is intended to be user-friendly (i.e., the reader can, presumably, relate easier to the content written from the personalised perspective, such as the we-narrative) on the one hand, and promotional, on the other hand. Arguably, the use of self-mentions we and our in COVID-19-related discourse and communication by both JH and UCL serve the purpose of promoting these universities' research, which is executed via the personalised dimension of the we-narrator (e.g., "at UCL we," "our experts," etc.). This contention is evocative of the argument made by Hyland ("The Communication"), who indicates that

Universities are no longer isolated ivory towers on the peripheries of society conducting obscure research projects of interest to only a handful of people. They must now make themselves relevant and engage more actively in the worlds outside their gates. Universities have discovered, or had the discovery forced upon them, a new mission: to give taxpayers better value by encouraging the dissemination of useful knowledge to the community through 'knowledge exchange'. (33)

Following Hyland ("The Communication"), the presence of the self-mentions in the corpus seems logical and even expected, given that the relevance of COVID-19 research conducted by JH and UCL should be promoted, exchanged with other scientific institutions, and disseminated. However, concurrently with the aforementioned user-friendliness, 
engagement and promotion, another reason that could, potentially, account for the occurrence of self-mentions in the present corpus refers to the conventions of academic writing that are used in the so-called Inner Circle of English (Kachru 3).

The construal of the English language as consisting of circles associated with its use involves the countries where it is spoken by the native speakers in the Inner Circle (e.g., the UK, USA), as the second and/or another official language in the Outer Circle (e.g., India, Singapore), and as the foreign language in the Expanding Circle (e.g., Italy, Romania). As previously mentioned in the article, the use of selfmentions is accepted in the current academic writing conventions in the UK and the USA, i.e., the Inner Circle of English (Ivanič). Moreover, academic writing in the Anglo-Saxon tradition in the countries of the Inner Circle of English is differentiated from academic writing discourse in other languages by the expected authorial presence, which is often expressed by the use of self-mentions. This observation is summarised by Ivanič, who argues that academic writing associated with the Inner Circle of English is never impersonal due to "the many social, cognitive and physical practices" (100). Further support of the contention that the presence of self-mentions is an intrinsic feature of academic writing in the countries of the Inner Circle of English is provided by Hyland ("Humble Servants?"). According to Hyland, academic writing in the Anglo-Saxon tradition typically employs self-mention in the humanities and the socalled "hard" sciences in order to "help construct an intelligent, credible, and engaging colleague, by presenting an authorial self firmly established in the norms of the discipline and reflecting an appropriate degree of confidence and authority" (Hyland "Humble Servants?" 216).

Presumably, content writers and communication officers at the COVID-19 research centres at JH and UCL employ self-mentions in the discursive content on the respective JH's and UCL's websites for the reasons that are enumerated by Hyland, i.e., to impart an image of authority and credibility, since these attributes, presumably, form an intrinsic feature of the Anglo-Saxon academic discourse community. I assume that it would be desirable to conduct interviews with the content writers at JH and UCL, respectively, in order to establish what motives 
might be involved in the use of self-mentions in the COVID-19-related discourse and communications disseminated by these two universities.

\section{Discussing RQ2: The Issue of Quantitative Differences between JH and UCL in the Occurrence of Self-mentions}

Apart from RQ1 that addresses the presence of self-mentions in the corpus, the other research question, RQ2, seeks to establish whether or not there would be quantitative differences between JH and UCL in the occurrence of self-mentions in COVID-19-related discourse and communication. To answer RQ2, a one-way analysis of variance (ANOVA) of the raw data was performed in order to discover statistically significant differences in the distribution of self-mentions common to $\mathrm{JH}$ and UCL, namely the self-mentions $I$, we, us, and our (see Table 2). The analysis did not yield statistically significant results at $p<.05[\mathrm{~F}(1)=$ $0.544, \mathrm{p}=.473]$. I interpret these findings as the similarity in the distribution of the self-mentions $I$, we, us, and our. The similarity could be reflective of the closeness and resemblance of computer-mediated communicative practices shared by $\mathrm{JH}$ and UCL, given that these universities are situated in the Inner Circle of English.

Notably, however, the normalised data point to the more substantial use of the self-mentions $I(\mathrm{~N}=18)$, we $(\mathrm{N}=57)$ and our $(\mathrm{N}=50)$ by UCL in comparison with that of $\mathrm{JH}(I \mathrm{~N}=9$, we $=42$, our $=2)$. I treat these findings as a manifestation of variation within the framework of similar computer-mediated communicative practices that are common to $\mathrm{JH}$ and UCL as far as COVID-19-related discourse and communication are concerned. To reiterate, the similarity of the use of self-mentions between $\mathrm{JH}$ and UCL is evident from the results of the ANOVA, which were not statistically significant. In terms of the similarity of the use of selfmention $I$, for instance, both JH and UCL employ it in the Frequently Asked Questions (FAQ) sections, for example "Will I be protected after just one dose?" (Vaccines FAQ). However, in addition to its FAQ section, UCL uses the self-mention $I$ more liberally as a part of the so-called individual $I$-narratives. Typically, they represent an individual researcher's, doctor's and/or a student's experiences and narratives 
associated with the coronavirus. This context of the use of the selfmention $I$ is illustrated by excerpt (3) below:

(3) I was one of the many students who have recently started in this role, and despite the initial confusion surrounding the programme, I have found that my colleagues and $\mathbf{I}$ are an enthusiastic and passionate cohort who are committed to offering their help in these unprecedented times. (Opinion: Graduate doctors need the support of their teams to add value)

Interestingly, a more frequent use of the self-mention $I$ by UCL seems to be counter-balanced by the frequently used self-mention our and the least frequent self-mention ourselves (notably, the latter is not employed by $\mathrm{JH}$ at all). Presumably, such choice of self-mentions contributes to the UCL's communicative strategy to present itself as an authoritative collective body, as emblematised by Excerpt (4):

(4) We pride ourselves on sharing a collective purpose, and are uncommonly willing and able to work together in a spirit of collaboration, mutual respect and trust. We partner with our worldclass NHS hospitals and with other collaborators, such as businesses, non-governmental organisations and policymaking bodies. Together, our collective efforts become greater than the sum of their parts. (Collaboration and Partnerships Driven by Purpose and Passion)

\section{Conclusions}

This article discusses a study that seeks to elucidate how self-mentions are employed in COVID-19-related discourse and communication disseminated to the public at large by $\mathrm{JH}$ and UCL. By means of conducting a quantitative analysis of self-mentions in the corpus of computer-mediated texts by JH and UCL on the topic of COVID-19 research, the study has established that both JH and UCL appear to employ such explicit means of authorial presence as the self-mentions $I$, $w e, u s$, and our. Whilst there is no statistically significant difference in the frequency of the aforementioned self-mentions between JH and UCL, the analysis of the normalised data indicated that UCL's discourse and 
communication about COVID-19 research are marked by a more substantial presence of the self-mentions $I$, we, and our. Given that the results of the one-way ANOVA are not significant, it seems possible to suggest that both JH and UCL share similar computer-mediated communicative practices of COVID-19 research dissemination. Arguably, the similarities in the use of self-mentions are supported by the discursive conventions of the Anglo-Saxon tradition of academic writing, as well as the communicative strategies of presenting these two universities as authoritative teams involved in COVID-19 research.

The present study has generated new knowledge about the use of self-mentions in relation to the current healthcare research and practices, since the prior studies on COVID-19-related discourse are focused primarily on macro-discursive features, such as frames and metaphors (e.g., Semino 55). This research, however, highlights the role of microdiscursive means, in particular, self-mentions, in the communication of scientific discourse on COVID-19 research that was critical in the time of the on-going COVID-19 pandemic.

\section{Works Cited}

American, British and Canadian Studies. Overview. Web. 15 Jan. 2021.

Bakhtin, Mikhail. Speech Genres and other Late Essays. Austin: U of Texas P, 1986.

Bieswanger, Markus. "Micro-linguistic Structural Features of Computer-mediated Communication." Pragmatics of Computer-Mediated Communication. Ed. Susan C. Herring, Dieter Stein, and Tuija Virtanen. Berlin: de Gruyter, 2013. 463-485.

Collaboration and Partnerships Driven by Purpose and Passion. University College London, 2021. Web. 28 Jan. 2021.

Coronavirus Resource Center. Johns Hopkins University, 2021. coronavirus.jhu.edu/. Web. 15 Jan. 2021.

COVID-19 Research at UCL. University College London, 2021. www.ucl.ac.uk/covid-19-research/. Web. 28 Jan. 2021.

Daily State-by-State Testing Trends. Johns Hopkins University, 2021. Web. 28 Jan. 2021.

Foucault, Michel. "Technologies of the Self." Technologies of the Self. Ed. Martin Luther, Huck Gutman, and Patrick H. Hutton. London: Tavistock, 1988.16-49. 
French, Ian, and John Lyne. "Acute Exacerbation of OCD Symptoms Precipitated by Media Reports of COVID-19." Irish Journal of Psychological Medicine 37.4 (2020): 291-294.

Hyland, Ken. "Authority and Invisibility: Authorial Identity in Academic Writing." Journal of Pragmatics 34.8 (2002): 1091-1112.

---. "Humble Servants of the Discipline? Self-mention in Research Articles." English for Specific Purposes 20.3 (2001): 207-226.

---. "Self-citation and Self-reference: Credibility and Promotion in Academic Publication." Journal of the American Society for Information Science and Technology 54.3 (2003): 251-259.

---. "The Communication of Expertise: Changes in Academic Writing." Scholarly Pathways: Knowledge Transfer and Knowledge Exchange in Academia. Ed. M. Gotti, S. Maci, and M. Sala. Bern: Lang, 2020. 33-56.

IBM. “IBM SPSS Statistics for Windows, version 20.0.” New York: IBM Corp. 2011.

Ivanič, Roz. Writing and Identity: The Discoursal Construction of Identity in Academic Writing. Amsterdam: Benjamins, 1998.

Jaspal, Rusi, and Brigitte Nerlich. "Social Representations, Identity Threat, and Coping amid COVID-19." Psychological Trauma: Theory, Research, Practice, and Policy 12.S1 (2020): S249.

Junnier, Frances. "Finding Voice in Biology: A Diachronic Analysis of Selfmention in the Discussions of an L2 Scholar." Journal of English for Academic Purposes 47 (2020): 1-17.

Kachru, Braj B. "World Englishes and Applied Linguistics." World Englishes 9.1 (1990): 3-20.

Koteyko, Nelya, et al. "The Dead Parrot and the Dying Swan: The Role of Metaphor Scenarios in UK Press Coverage of Avian Flu in the UK in 20052006." Metaphor and Symbol 23.4 (2008): 242-261.

Lambrecht, Kathryn. "Tracking the Differentiation of Risk: The Impact of Subject Framing in CDC Communication Regarding COVID-19.” Journal of Business and Technical Communication 35.1 (2021): 94-100.

Majumder, Maimuna S., and Kenneth D. Mandl. "Early in the Epidemic: Impact of Preprints on Global Discourse about COVID-19 Transmissibility." The Lancet Global Health 8.5 (2020): 627-630.

Morgan, Marcus. "Why Meaning-making Matters: The Case of the UK Government's COVID-19 Response." American Journal of Cultural Sociology 8.3 (2020): 270-323.

Nerlich, Brigitte. "War on Foot and Mouth Disease in the UK, 2001: Towards a Cultural Understanding of Agriculture." Agriculture and Human Values 21.1 (2004): 15-25.

Nerlich, Brigitte, and Christopher Halliday. "Avian Flu: The Creation of Expectations in the Interplay between Science and the Media." Sociology of Health \& Illness 29.1 (2007): 46-65.

Nerlich, Brigitte, Craig Hamilton, and Victoria Rowe. "Conceptualising Foot and Mouth Disease: The Socio-cultural Role of Metaphors, Frames and Narratives." Metaphorik.de 2 (2002): 90-108. 
Nerlich, Brigitte, and Nelya Koteyko. "Crying Wolf? Biosecurity and Metacommunication in the Context of the 2009 Swine Flu Pandemic." Health \& Place 18.4 (2012): 710-717.

Opinion: Graduate Doctors Need the Support of Their Teams to Add Value. University College London, 2021. Web. 28 Jan. 2021.

Palander-Collin, Minna, and Minna Nevala. "Person Reference and Democratization in British English." Language Sciences 79 (2020): 101265.

Pikhart, Marcel. "Cultural Discourse in Human-Computer Interactions: Linguistic Aspects of Digital Communication." Advanced Multimedia and Ubiquitous Engineering. Ed. J. J. Park, V. Loia, Y. Pan, and Y. Sung. Singapore: Springer, 2021. 121-126.

Scott, Mike. WordSmith Tools version 5. Liverpool: Lexical Analysis Software $122,2008$.

Semino, Elena. "Not Soldiers but Fire-fighters'-Metaphors and Covid19." Health Communication 36.1 (2021): 50-58.

Szczygłowska, Tatiana. "Creating the Authorial Self in Academic Texts: Evidence from the Expert's Style of Writing." English Studies at NBU 6.1 (2020): 69-94.

Vaccines FAQ. Johns Hopkins University, 2021. coronavirus.jhu.edu/vaccines/vaccines-faq. Web. 15 Jan. 2021.

Wallis, Patrick, and Brigitte Nerlich. "Disease Metaphors in New Epidemics: The UK Media Framing of the 2003 SARS Epidemic." Social Science \& Medicine 60.11 (2005): 2629-2639.

Webber-Ritchey, Kashica J., et al. "COVID-19: Qualitative Research with Vulnerable Populations." Nursing Science Quarterly 34.1 (2021): 13-19.

Wicke, Philipp, and Marianna M. Bolognesi. "Framing COVID-19: How We Conceptualize and Discuss the Pandemic on Twitter." PLoS ONE 15(9): (2020): 1-24.

Zhu, Hongqiang. "Countering COVID-19-related Anti-Chinese Racism with Translanguaged Swearing on Social Media." Multilingua 39.5 (2020): $607-$ 616.

Zou, Hang, and Ken Hyland. "Academic Blogging: Scholars' Views on Interacting with Readers." Ibérica: Revista de la Asociación Europea de Lenguas para Fines Específicos (AELFE) 39 (2020): 267-294. 